Published in final edited form as:

Nano Lett. 2007 October ; 7(10): 3071-3079. doi:10.1021/n1071547f.

\title{
Labeling of Mesenchymal Stem Cells by Bioconjugated Quantum Dots
}

\author{
Bhranti S. Shah ${ }^{\dagger}$, Paul A. Clark ${ }^{\ddagger}$, Eduardo K. Moioli ${ }^{\dagger}$, Michael A. Stroscio ${ }^{\S}$, and Jeremy J. \\ $\mathrm{Mao}^{\dagger,}{ }^{*}$ \\ ${ }^{\dagger}$ College of Dental Medicine, Department of Biomedical Engineering, Fu Foundation School of \\ Engineering and Applied Sciences, Columbia University, New York, New York 10032 \\ ¥Department of Neurological Surgery, University of Wisconsin at Madison, Madison, Wisconsin \\ 53792
}

§Department of Bioengineering, University of Illinois at Chicago, Chicago, Illinois 60607

\begin{abstract}
Long-term labeling of stem cells during self-replication and differentiation benefits investigations of development and tissue regeneration. We report the labeling of human mesenchymal stem cells (hMSCs) with RGD-conjugated quantum dots (QDs) during self-replication, and multilineage differentiations into osteogenic, chondrogenic, and adipogenic cells. QD-labeled hMSCs remained viable as unlabeled hMSCs from the same subpopulation. These findings suggest the use of bioconjugated QDs as an effective probe for long-term labeling of stem cells.
\end{abstract}

Stem cells are central to the understanding of native development and tissue regeneration. Stem cells overcome many of the limitations of tissue or organ transplantation such as donor shortage and donor site morbidity, pathogen transmission, and immune incompatibility. ${ }^{1}$ Stem cells give rise to tissue progenitor cells, which in turn differentiate into tissue-forming cells. ${ }^{2-4}$ For example, mesenchymal stem cells (MSCs) give rise to osteoprogenitor cells, which in turn differentiate into bone-forming osteoblasts. ${ }^{5-7}$ In addition to osteogenic differentiation, MSCs are capable of differentiating into chondrocytes, myocytes, tenocytes, adipocytes, fibroblasts, etc. ${ }^{6,8-10}$ Without telomere manipulations, MSCs undergo a substantial, but not unlimited, number of population doublings. ${ }^{6,7,11}$ When stem cells or their progeny are applied to regenerate tissues and organs, there is a critical need to delineate the relative contribution to the regenerated tissues and organs from delivered cells versus host cells. Thus, long-term labeling of stem cells is critically needed in the field of regenerative medicine for understanding their fate, migration, and contribution to the regenerating tissues. ${ }^{10,12}$ Reliable and cytocompatible labeling of stem cells is also critically

\footnotetext{
(C) 2007 American Chemical Society

*Corresponding author. jmao@ columbia.edu. Telephone: (212) 305-4475. Fax: (212) 342-0199. Jeremy J. Mao, DDS, Ph.D., 630 W. 168 St., PH7E, Columbia University Medical Center, New York, New York 10032.

Supporting Information Available: Isolation and culture of human mesenchymal stem cells (hMSCs); preparation of bioconjugated QDs; incubation of human mesenchymal stem cells with bioconjugated QDs; QD labeling of human mesenchymal stem cells during proliferation; QD labeling of human mesenchymal stem cells during multilineage differentiation; bright-field and fluorescence microscopy; data analysis and statistics. This material is available free of charge via the Internet at http://pubs.acs.org.
} 
needed in developmental biology so that the proliferation, apoptosis, and differentiation of various cell lineages can be tracked.

Among all cell labeling probes, organic fluorophores such as rhodamine, fluorescein, DAPI, DsRed, and alexa488 have been widely utilized in cell biology and developmental biology. ${ }^{13-16}$ Organic dyes are easy to use, relatively inexpensive, and are capable of labeling cells in culture for short time. However, organic fluorophores may photobleach and lose fluorescence and therefore are not typically used to label cells for substantial time. Fluorescence emission of organic dyes is quenched upon conjugation to biological molecules as dye molecules start to form nonfluorescent derivatives. ${ }^{15,16}$ Organic dyes are sensitive to changes in local $\mathrm{pH}$ and chemical degradation and accordingly may readily disintegrate, lose fluorescence, or yield false positive results. ${ }^{14-16}$ Additionally, the broad emission spectra of organic dyes can overlap and may lead to false positive signals.

Genetically encoded fluorescent proteins such as green fluorescent protein (GFP) have been widely used for cell labeling. GFPs are spontaneous fluorescent proteins isolated from a jellyfish, Aequorea victoria. ${ }^{17,18}$ GFP transduces the blue chemiluminescence of aequorin into green fluorescent light by energy transfer. ${ }^{18,19}$ GFPs are typically transfected into the cells via retrovirus, lentivirus, or nonviral approaches. ${ }^{19}$ In comparison with organic dyes, GFPs have a number of advantages such as better photostability and $\mathrm{pH}$ tolerance in addition to longer luminescence time. However, GFPs suffer from a number of intrinsic deficiencies such as sensitivity to proteolytic enzymes and overlap with autofluorescence signal, thus making it difficult for in vivo cell tracking. ${ }^{20,21}$ Like organic fluorophores, GFPs have a critical drawback of narrow excitation and wide emission spectrum. It is difficult to excite multiple fluorescent proteins simultaneously with a single excitation source. ${ }^{20,22}$

Quantum dots (QDs) are small, light-emitting semiconductor nanocrystals, typically in the size range of 2-10 nm. ${ }^{23-27}$ QDs are generally composed of atoms from groups II-VI (e.g., $\mathrm{CdSe}, \mathrm{CdTe}, \mathrm{CdS}$, and ZnSe) or III-V (e.g., InP and InAs) of the periodic table, and are nanoparticles with physical dimensions smaller than the excitation Bohr radius. ${ }^{16,28}$ The diameter of QDs determines their emission and excitation spectra and can be fine-tuned. ${ }^{29,30}$ After years of nonbiological applications, highly luminescent QDs were made water soluble and tethered to biomolecules for cell labeling. ${ }^{31,32}$ Subsequently, the fluorescence yield of bioconjugated QDs has been enhanced. ${ }^{33}$ Currently, commercially available QDs are tailored for cell labeling. In contrast to organic dyes or fluorescent proteins, QDs have several distinctive advantages, especially for long-term cell labeling and in vivo cell tracking. QDs are generally photostable and maintain fluorescent intensity in cell culture for a prolonged time. ${ }^{16,28,34}$ The higher absorbance rate of QDs is translated into higher fluorescence intensity. For example, the fluorescence intensity of a single cadmium selenide QD is equivalent to that of approximately 20 rhodamine molecules. ${ }^{32}$ QDs are approximately 10-20 times brighter than fluorescent proteins. ${ }^{34}$ The narrow emission spectrum and broad excitation spectrum of QDs enable multiplexing by a single wavelength activation. ${ }^{20,22,29,34-37}$ Different cell lineages can be labeled and potentially tracked via multicolor QD probes for studies of both native development and tissue regeneration, given that biological tissues and organs contain multiple cell lineage..$^{29,34,35,37}$ 
QDs have been shown to label several cell lineages such as tumor cells, endothelial cells, erythrocytes, and fibroblasts. ${ }^{16,28,31,38}$ However, little is known whether stem cells can be effectively labeled by QDs during both proliferation and multilineage differentiation for long term. Stem cells, by definition, are capable of self-replication and differentiation into multiple lineages. ${ }^{2-4}$ In the present study, we labeled human mesenchymal stem cells (hMSCs) with bioconjugated quantum dots during proliferation as well as during differentiations into osteogenic, chondrogenic, and adipogenic cells. Our data demonstrate that QD-labeled human mesenchymal stem cells were viable and continued to proliferate for the tested 22 days, similar to unlabeled hMSCs of the same subpopulation. Bioconjugated QDs remained visible in hMSCs after differentiation into osteogenic, chondrogenic, and adipogenic lineages, as evidenced by the expression of matrix biosynthesis markers, similar to the differentiation capacity of unlabeled hMSCs. The effective concentration and incubation time of bioconjugated quantum dots were determined for broad applications.

\section{QD Labeling of Human Mesenchymal Stem Cells during Proliferation}

An essential question for QD labeling of stem cells is cytocompatibility over long term and during proliferation. We first optimized effective QD concentrations for labeling hMSCs and found that 20 and $50 \mathrm{nM}$ QD concentrations effectively labeled hMSCs, whereas 0.5 and $5 \mathrm{nM}$ QD concentrations failed to yield effective labeling (data not shown). Accordingly, we elected to use $30 \mathrm{nM}$ QD concentration for subsequent experiments. Additionally, overnight incubation was found to be effective in labeling hMSCs, whereas QD labeling of hMSCs for $5 \mathrm{~min}, 30 \mathrm{~min}$, and $2 \mathrm{~h}$ failed to yield satisfactory fluorescence (data not shown). With the knowledge of effective QD concentration and labeling time, we labeled hMSCs with the bioconjugated QDs at the optimized $30 \mathrm{nM}$ concentration and overnight incubation. Following removal of unbound QDs, we continued to culture and expand QD-labeled hMSCs for up to 22 days. Figure 1 shows bright-field, fluorescent, and overlay images of QD-labeled MSCs after days 0, 4, 7, and 22 of cell proliferation. QDlabeled human MSCs continued to proliferate after continuous culture expansion for day 0 (Figure 1a1,a2), day 4 (Figure 1b1,b2), day 7 (Figure 1c1, c2), and day 22 (Figure 1d1,d2). QDs were internalized after overnight incubation and were visible in the cytoplasm of cells (Figure 1e1,e2). Interestingly, bioconjugated QD aggregates did not appear to enter the nuclei (Figure 1e1,e2).

Cell viability of QD-labeled hMSCs and unlabeled hMSCs (from the same subpopulation) measured by trypan blue exclusion lacked significant difference after $0,4,7$, and 22 days of cell culture (Figure 2a), suggesting that the present bioconjugated QDs are cytocompatible and did not induce cell death. Fluorescence activated cell sorting (FACS) was used to sort QD-labeled hMSCs and unlabeled hMSCs as controls, following overnight QD incubation at $30 \mathrm{nM}$ concentration. In comparison with a low FACS yield of unlabeled hMSCs (Figure 2b,c), QD-labeled hMSCs had a high fluorescent yield (Figure 2d,e). This was verified by quantitative data in Figure $2 \mathrm{f}$ showing that $96 \%$ of QD-labeled hMSCs fluoresced in $6005 \pm$ $20 \mathrm{~nm}$ in comparison with only $6.5 \%$ of unlabeled hMSCs in the signal range of $605 \pm 20$ $\mathrm{nm}$. A common challenge with cell tracking is that the labeling dyes leach out from the cell over time, leading to possible uptake of dyes by other cells and introducing false positive artifacts. We started to address this issue by using a transwell culture system. QD-labeled 
hMSCs were cultured in the insert of the transwell system. Unlabeled hMSCs were cultured underneath in the transwell plate. The diameter of the pores in the insert is $400 \mathrm{~nm}$, much larger than the diameter of QDs in the range of 2-10 nm. QD-labeled hMSCs were observed under fluorescent microscope during the tested 1, 4, and 7 days (Figure 3a1,b1,c1), no apparent QD labeling was observed in the unlabeled hMSCs cultured underneath in the same medium (Figure 3a3,b3,c3). Bright-field images revealed the presence of QD-labeled hMSCs (Figure 3a-c) and unlabeled hMSCs (Figure 3a2-c2) up to the tested 7 days. These data suggest that QDs that have been extruded by hMSCs cultured on the insert are not taken up by hMSCs cultured underneath in the transwell plate up to the tested 7 days in culture.

\section{QD Labeling of Human Mesenchymal Stem Cells during Osteogenic, Chondrogenic, and Adipogenic Differentiations}

With the knowledge of the efficacy of QD labeling following up to 22 days of proliferation, we asked the next logical question of whether QD labeling interferes with the differentiation capacity of hMSCs toward multiple cell lineages. Per our prior differentiation methods, hMSCs were induced to differentiate into osteoblasts (hMSC-Ob), chondrocytes (hMSCCy), and adipocytes (hMSC-Ad). ${ }^{10,39-42}$ Figure 4a shows that QD-labeled hMSCs treated with osteogenic supplemented medium for 7 days were stained positively to alkaline phosphatase (ALP), similar to our previous work. ${ }^{38,39,40,43,44}$ The QD-labeled hMSCs during osteogenic differentiation showed somewhat more rounded morphology in monolayer culture (Figure $4 \mathrm{~b}$ ) in comparison with hMSCs without osteogenic differentiation (e.g., Figure 1a-d). The corresponding fluorescent (Figure 4b1) and overlay (Figure 4b2) images showed that the presently used QDs labeled the hMSC-derived osteogenic cells, suggesting that the presently used QDs can label stem-cell-derived lineage-specific cells. ALP content lacked significant difference between QD-labeled and unlabeled hMSCs during osteogenic differentiation for day 0 and day 14 (Figure 4c). Calcium content, an end-stage osteogenic differentiation marker, also lacked significant difference between QD-labeled hMSCs and unlabeled hMSCs during osteogenic differentiation (Figure 4d), suggesting that QD labeling does not interfere with the capacity of hMSCs to elaborate a mineralized matrix.

Chondrogenic differentiation of hMSCs was tested with or without QD labeling per our previous approaches. ${ }^{9,40,43,45}$ QD labeling was visible in the pellet as revealed by brightfield image of a chondrogenic pellet (Figure 5a), fluorescent image of the same chondrogenic pellet (Figure 5b), and an overlay of bright-field and fluorescent images of the chondrogenic pellet (Figure 5c). When cultured in chondrogenic stimulating medium, QDlabeled hMSCs showed continuous pellet formation (Figure 5e), similar to hMSCs without QD labeling (Figure 5d). Glycosaminoglycan (GAG) content, an indication of biosynthesis of cartilage matrix, showed a lack of significant difference between QD-labeled hMSCs and unlabeled hMSCs during chondrogenic differentiation up to the tested 28 days (Figure 5f).

Adipogenic differentiation of hMSCs followed our previously developed methods. ${ }^{40-42,46}$ Intracellular lipids began to accumulate in QD-labeled or unlabeled hMSCs treated with adipogenic supplements during 28 days of culture (Figure 6a). Similar to hMSCs, hMSCderived osteogenic and chondrogenic cells, bioconjugated QDs remained in the cytoplasm of 
hMSC-derived adipocytes during differentiation (Figure 6b,c). Oil-red O staining revealed the formation of a substantial amount of lipid vacuoles by unlabeled hMSCs (Figure 6d) as well as QD-labeled hMSCs (Figure 6e) during adipogenic differentiation. In conjunction with our previous findings of the expression of PPAR $\gamma 2$ and other adipogenic markers by hMSC-derived adipogenic cells and glycerol production, ${ }^{40,46}$ glycerol content of unlabeled hMSCs, and QD-labeled hMSCs lacked significant difference up to the tested 28 days (Figure 6f), suggesting that QD labeling does not interfere with adipogenic differentiation of hMSCs.

These findings represent an original demonstration of long-term labeling of human mesenchymal stem cells during both proliferation and multilineage differentiation into osteogenic, chondrogenic, and adipogenic cells by bioconjugated quantum dots.

Bioconjugated QDs are endocytosed and remain in the endosomes of expanded hMSCs up to tested 22 days of proliferation. Although bioconjugated QDs have been utilized to label tumor cells, endothelial cells, and fibroblasts, ${ }^{16,28,34,38}$ stem cells present potential challenges for QD labeling because stem cells, including the presently used mesenchymal stem cells, undergo self-renewal and multilineage differentiation. ${ }^{10,11,49,50}$ Cytoskeleton of MSCs is known to undergo substantial reorganization during the differentiation into lineagespecific cells such as osteoblasts and chondrocytes. ${ }^{45,51,52}$ It is remarkable that bioconjugated QDs are continuously present in both hMSCs and hMSC-derived osteogenic, chondrogenic, and adipogenic cells for up to the tested 28 days as shown in the present study. Although tumor cells readily proliferate, many types of tumor cells do not differentiate into multiple cell lineages. Thus, the present demonstration of QD labeling of hMSCs during the differentiation into multiple lineages such as osteogenic, chondrogenic, and adipogenic cells is likely useful for delineating the relative contribution of various cell lineages to the regeneration of tissues and organs. Additional experiments are warranted to determine the labeling efficacy of bioconjugated QDs in differentiated cells. For example, the synovial joint condyle consists of chondrocytes and osteoblasts, in addition to progenitor cells, that interact during both native development and tissue regeneration. ${ }^{53-56}$ Long-term labeling of stem cells, osteoblasts, and chondrocytes is beneficial for understanding the relative contribution to the morphogenesis of either native or engineered synovial joint condyles.

QDs in the present study are apparently endocytosed as aggregates into the cytoplasm. This is consistent with previous findings in other cell types such as tumor cells. ${ }^{57,58}$ QDs without bioconjugation usually do not bind to cell surface molecules and instead need to be coated to peptides or proteins that serve as ligands for integrin binding on cell surface. Another indirect indication of endocytosis of QDs is our present observation, consistent with QD labeling of tumor cells, that QD aggregates apparently do not enter the nuclei, given the inability of the nuclear pore to internalize QDs. Consistent with several previous reports, we found that bioconjugated QDs were internalized into the cytoplasm and not translocated into the nuclei. Bioconjugated QDs cluster into particles that are greater than the size of nuclear pores. Alternatively, the radius of QDs (hydrodynamic radius $\sim 25 \mathrm{~nm}$ ) exceeds the passive diffusion of the QD-RGD assembly through the nuclear pore complex (hydrodynamic radius $\sim 5 \mathrm{~nm}) .{ }^{59}$ Additional experiments are warranted to investigate why bioconjugated QDs do 
not enter the nucleus. Furthermore, RGD-conjugated QDs may have been packaged in the endosomes and/or the lysosomes. ${ }^{60}$ The present work used RGD peptide for integrin binding, similar to previous approaches using GFE (CGFECVRQCPERC), F3 (KDEPQRRSARLSAKPAPPKPEPKPKKAPAKK), andLyP-1(CGNK-RTRGC) peptides for integrin binding on endothelial cells, blood vessels, and tumor cells in various tumors, and lymphatic vessels and tumor cells in certain tumors respectively. ${ }^{61}$ In the present study, semiconductor nanocrystals are bound to CGGGRGD peptide through the thiol linkage between the cysteine (C) amino acid and the semiconductor nanocrystals. The GGG sequences of glycine (G) amino acids provide a spacer in the amino acid chain, and the RGD sequence has selective binding affinity to specialized transmembrane cellular structures such as integrins.

A recent communication confirms our finding that QD labeling does not inhibit ALP activity of bone marrow progenitor cells but shows inhibition of osteopontin expression upon QD labeling. ${ }^{62}$ Because osteopontin was not assayed in the present study, we have yet to confirm or dispute the attenuated osteopontin expression. A careful examination reveals several important differences between their and our work. Their bone marrow cells are immortalized in contrast to primary MSCs in the present study. Immortalized cells may not express certain matrix markers. ${ }^{63}$ Only a qualitative osteopontin image was presented without quantitative osteopontin assay. The present data showing comparable $\mathrm{Ca}^{++}$ production, an end-stage osteogenic differentiation marker, by QD-labeled hMSCs and unlabeled hMSCs during osteogenic differentiation indicate that osteogenic differentiation of hMSCs was not inhibited by QD labeling. The QDs they used were from a different source, had a different emission spectrum, and were not bioconjugated to the same peptide. Interestingly, another recent communication by the same group has suggested that QD labeling inhibits the elaboration of chondrogenic matrix. ${ }^{64}$ Only qualitative mRNA expression and histological images of selected chondrogenic markers were shown without quantitative data. In contrast, we have shown comparable quantitative GAG synthesis between QD-labeled hMSC-derived chondrocytes and unlabeled hMSC-derived chondrocytes. Our present demonstration of the comparable ability of QD-labeled hMSCs in the differentiation into adipogenic cells provides further evidence that QD labeling may not substantially interfere with hMSC differentiation into multiple mesenchymal lineages. In light of these recent communications, our ongoing studies will monitor an array of osteogenic and chondrogenic markers by real- time PCR, quantitative protein assays (ELISA), and matrix structural analysis. A recent communication confirms our finding that QDs effectively label human bone-marrow-derived mesenchymal stem cells, although the experiment was short term and did not label MSC progenies. ${ }^{47}$

QD labeling of stem cells needs to be further studied to test the labeling and in vivo tracking of not only mesenchymal stem cells but also embryonic, hematopoietic, epithelial, neural, and other stem cells. When cells divide, the total number of QDs is likely divided, not necessarily 50:50, between two daughter cells. ${ }^{48}$ Upon endless cell divisions, it is probable that the initial number of QDs is divided between parent and daughter cells. However, this can be compensated by using higher QD doses upon initial cell labeling. The cost of QD labeling currently is a barrier for large-scale studies. QDs can be tethered to single peptides and DNA fragments for broader applications, ${ }^{27,30,65}$ in addition to the present approach of labeling cells. Human MSCs in the present study were isolated and expanded from multiple 
donors of both genders and various ages. The majority of cell labeling studies have concluded that properly capped and bioconjugated QDs are not toxic to cells. ${ }^{34,35,57,65-69}$ Now we have found that QD-labeled mesenchymal stem cells are capable of proliferation and differentiation. Given the proliferation and differentiation capacity of stem cells, additional toxicity studies of QD labeling of hMSCs and other stem cells likely will further contribute to our understanding of the application of QDs in cell biology, developmental biology, and regenerative medicine. Together, bioconjugated quantum dots (QDs) are capable of labeling human mesenchymal stem cells (hMSCs) during proliferation for the tested 22 days. Cell survival assays indicate that QD-labeled hMSCs are as viable as unlabeled hMSCs from the same subpopulation. These findings suggest that QDs are effective probes for self-replicating stem cells. During the differentiation of hMSCs into chondrogenic, osteogenic, and adipogenic cells, QDs continued to reside in differentiating cells. The multilineage differentiation of hMSCs into chondrocytes, osteoblasts, and adipocytes was verified by respective matrix biosynthesis markers such as glycosaminoglycan content, alkaline phosphatase, calcium production, and glycerol content as well as histological dyes. Taken together, these findings represent an original investigation of the labeling of stem cells with bioconjugated quantum dots and suggest that bioconjugated quantum dots may be an effective probe for labeling stem cells during both proliferation and differentiation into multiple lineages.

\section{Supplementary Material}

Refer to Web version on PubMed Central for supplementary material.

\section{Acknowledgments}

We thank Sarah Kennedy and Dinakar Ramadurai for technical assistance. We appreciate the administrative assistance from Richard Abbott and Janina Acloque. This research was supported by NIH grants DE15391 and EB02332 to J.J.M.

\section{References}

1. Fairchild PJ, Nolan KF, Cartland S, Waldmann H. Int Immunopharmacol. 2005; 5:13-21. [PubMed: 15589455]

2. Prockop D. J Science. 2001; 293:211-212.

3. Parker GC, Nastassova-Kristeva M, Eisenberg LM, Rao MS, Williams MA, Sanberg PR, English D. Stem Cells Dev. 2005; 14:463-469. [PubMed: 16305331]

4. Dominici M, Le BK, Mueller I, Slaper-Cortenbach I, Marini F, Krause D, Deans R, Keating A, Prockop D, Horwitz E. Cytotherapy. 2006; 8:315-317. [PubMed: 16923606]

5. Friedenstein AJ, Chailakhjan RK, Lalykina KS. Cell Tissue Kinet. 1970; 3:393-403. [PubMed: 5523063]

6. Caplan AI. J Orthop Res. 1991; 9:641-650. [PubMed: 1870029]

7. Colter DC, Sekiya I, Prockop DJ. Proc Natl Acad Sci USA. 2001; 98:7841-7845. [PubMed: 11427725]

8. Pittenger MF, Mackay AM, Beck SC, Jaiswal RK, Douglas R, Mosca JD, Moorman MA, Simonetti DW, Craig S, Marshak DR. Science. 1999; 284:143-147. [PubMed: 10102814]

9. Alhadlaq A, Mao JJ. Stem Cells Dev. 2004; 13:436-448. [PubMed: 15345137]

10. Marion NW, Mao JJ. Methods Enzymol. 2006; 420:339-361. [PubMed: 17161705]

11. Song L, Webb NE, Song Y, Tuan RS. Stem Cells. 2006; 24:1707-1718. [PubMed: 16574750] 
12. Rahaman MN, Mao JJ. Biotechnol Bioeng. 2005; 91:261-284. [PubMed: 15929124]

13. Terasaki M. Methods Cell Biol. 1989; 29:125-135. [PubMed: 2643757]

14. Srivastava SC, Straub RF, Meinken GE. Acta Radiol Suppl. 1990; 374:103-108. [PubMed: 1966954]

15. Sugaya A, Chudler EH, Byers MR. Brain Res. 1994; 653:330-334. [PubMed: 7982069]

16. Marks KM, Nolan GP. Nat Methods. 2006; 3:591-596. [PubMed: 16862131]

17. Lippincott-Schwartz J, Smith CL. Curr Opin Neurobiol. 1997; 7:631-639. [PubMed: 9384543]

18. Stahl A, Wu X, Wenger A, Klagsbrun M, Kurschat P. FEBS Lett. 2005; 579:5338-5342. [PubMed: 16194535]

19. Daly CJ, McGrath JC. Pharmacol Ther. 2003; 100:101-118. [PubMed: 14609715]

20. Jaiswal JK, Goldman ER, Mattoussi H, Simon SM. Nat Methods. 2004; 1:73-78. [PubMed: 16138413]

21. Gao X, Nie S. Methods Mol Biol. 2005; 303:61-71. [PubMed: 15923675]

22. Alivisatos AP, Gu W, Larabell C. Annu Rev Biomed Eng. 2005; 7:55-76. [PubMed: 16004566]

23. Frangioni JV. Curr Opin Chem Biol. 2003; 7:626-634. [PubMed: 14580568]

24. Frangioni JV. Nat Biotechnol. 2006; 24:326-328. [PubMed: 16525407]

25. Bruchez MP. Curr Opin Chem Biol. 2005; 9:533-537. [PubMed: 16125995]

26. Chan WC. Biol Blood Marrow Transplant. 2006; 12:87-91. [PubMed: 16399591]

27. Medintz IL, Clapp AR, Brunel FM, Tiefenbrunn T, Uyeda HT, Chang EL, Deschamps JR, Dawson PE, Mattoussi H. Nat Mater. 2006; 5:581-589. [PubMed: 16799548]

28. Alivisatos P. Nat Biotechnol. 2004; 22:47-52. [PubMed: 14704706]

29. Jaiswal JK, Simon SM. Trends Cell Biol. 2004; 14:497-504. [PubMed: 15350978]

30. Delehanty JB, Medintz IL, Pons T, Brunel FM, Dawson PE. Bioconjugate Chem. 2006; 17:920927.

31. Bruchez M, Moronne M, Gin P, Weiss S, Alivisatos AP Jr. Science. 1998; 281:2013-2016. [PubMed: 9748157]

32. Chan WC, Nie S. Science. 1998; 281:2016-2018. [PubMed: 9748158]

33. Peng ZA, Peng X. J Am Chem Soc. 2001; 123:183-184. [PubMed: 11273619]

34. Gao X, Cui Y, Levenson RM, Chung LW, Nie S. Nat Biotechnol. 2004; 22:969-976. [PubMed: 15258594]

35. Mattheakis LC, Dias JM, Choi YJ, Gong J, Bruchez MP, Liu J, Wang E. Anal Biochem. 2004; 327:200-208. [PubMed: 15051536]

36. Chang E, Miller JS, Sun J, Yu WW, Colvin VL, Drezek R, West JL. Biochem Biophys Res Commun. 2005; 334:1317-1321. [PubMed: 16039606]

37. Fu A, Gu W, Larabell C, Alivisatos AP. Curr Opin Neurobiol. 2005; 15:568-575. [PubMed: 16150591]

38. Shi P, Chen H, Cho MR, Stroscio MA. IEEE Trans Nanobiosci. 2006; 5:15-19.

39. Moioli EK, Hong L, Guardado J, Clark PA, Mao JJ. Tissue Eng. 2006; 12:537-546. [PubMed: 16579687]

40. Alhadlaq A, Elisseeff JH, Hong L, Williams CG, Caplan AI, Sharma B, Kopher RA, Tomkoria S, Lennon DP, Lopez A, Mao JJ. Ann Biomed Eng. 2004; 32:911-923. [PubMed: 15298429]

41. Stosich MS, Mao JJ. Plast Reconstr Surg. 2007; 119:71-83. [PubMed: 17255658]

42. Stosich MS, Mao JJ. Semin Plast Surg. 2005; 19:251-260.

43. Alhadlaq A, Mao JJ. J Bone Joint Surg Am. 2005; 87:936-944. [PubMed: 15866954]

44. Marion NW, Liang W, Reilly GC, Day DE, Rahaman MN, Mao JJ. Mech Adv Mater Struct. 2005; 12:1-8.

45. Yourek GA, Patel R, McCormick S, Reilly GC, Mao JJ. Biol Nanostruct Appl Nanostruct Biol. 2004; 2:69-97.

46. Peptan IA, Hong L, Mao JJ. Plast Reconstr Surg. 2006; 117:1462-1470. [PubMed: 16641714]

47. Seleverstov O, Zabirnyk O, Zscharnack M, Bulavina L, Nowicki M, Heinrich JM, Yezhelyev M, Emmrich F, O’Regan R, Bader A. Nano Lett. 2006; 6:2826-32. [PubMed: 17163713] 
48. Lagerholm BC, Wang M, Ernst LA, Ly DH, Liu H, Bruchez MP, Waggoner AS. Nano Lett. 2004; 4:2019-22.

49. Gregory CA, Prockop DJ, Spees JL. Exp Cell Res. 2005; 306:330-335. [PubMed: 15925588]

50. Caplan AI, Dennis JE. J Cell Biochem. 2006; 98:1076-1084. [PubMed: 16619257]

51. Rodriguez JP, Gonzalez M, Rios S, Cambiazo V. J Cell Biochem. 2004; 93:721-731. [PubMed: 15660416]

52. Yourek G, Hussain MA, Mao JJ. ASAIO J. 2007; 53:219-218. [PubMed: 17413564]

53. Archer CW, Dowthwaite GP, Francis-West P. Birth Defects Res Part C. 2003; 69:144-155.

54. Mao JJ. Biol Cell. 2005; 97:289-301. [PubMed: 15836429]

55. Martin I, Miot S, Barbero A, Jakob M, Wendt D. J Biomech. 2007; 40:750-765. [PubMed: 16730354]

56. Wendt D, Jakob M, Martin I. J Biosci Bioeng. 2005; 100:489-494. [PubMed: 16384786]

57. Jaiswal JK, Mattoussi H, Mauro JM, Simon SM. Nat Biotechnol. 2003; 21:47-51. [PubMed: 12459736]

58. Estrada CR, Salanga M, Bielenberg DR, Harrell WB, Zurakowski D, Zhu X, Palmer MR, Freeman MR, Adam RM. Cancer Res. 2006; 66:3078-3086. [PubMed: 16540657]

59. Keminer O, Peters R. Biophys J. 1999; 77:217-228. [PubMed: 10388751]

60. Hanaki K, Momo A, Oku T, Komoto A, Maenosono S, Yamaguchi Y, Yamamoto K. Biochem Biophys Res Commun. 2003; 302:496-501. [PubMed: 12615061]

61. Akerman ME, Chan WC, Laakkonen P, Bhatia SN, Ruoslahti E. Proc Natl Acad Sci USA. 2002; 99:12617-12621. [PubMed: 12235356]

62. Hsieh SC, Wang FF, Lin CS, Chen YJ, Hung SC, Wang Y. J Biomaterials. 2006; 27:1656-1664.

63. Mallein-Gerin F, Ruggiero F, Quinn TM, Bard F, Grodzinsky AJ, Olsen BR, van der RM. Exp Cell Res. 1995; 219:257-265. [PubMed: 7628541]

64. Hsieh SC, Wang FF, Hung SC, Chen YJ, Wang YJ. J Biomed Mater Res Part B. 2006; 79:95-101.

65. Dubertret B, Skourides P, Norris DJ, Noireaux V, Brivanlou AH, Libchaber A. Science. 2002; 298:1759-1762. [PubMed: 12459582]

66. Ballou B, Lagerholm BC, Ernst LA, Bruchez MP, Waggoner AS. Bioconjugate Chem. 2004; 15:79-86.

67. Larson DR, Zipfel WR, Williams RM, Clark SW, Bruchez MP, Wise FW, Webb WW. Science. 2003; 300:1434-1436. [PubMed: 12775841]

68. Voura EB, Jaiswal JK, Mattoussi H, Simon SM. Nat Med. 2004; 10:993-998. [PubMed: 15334072]

69. Hoshino A, Hanaki K, Suzuki K, Yamamoto K. Biochem Biophys Res Commun. 2004; 314:4653. [PubMed: 14715244]

70. Zhang X, Ziran N, Goater JJ, Schwarz EM, Puzas JE, Rosier RN, Zuscik M, Drissi H, O’Keefe RJ. Bone. 2004; 34:809-817. [PubMed: 15121012] 
Brightfield

Fluorescent

Overlay

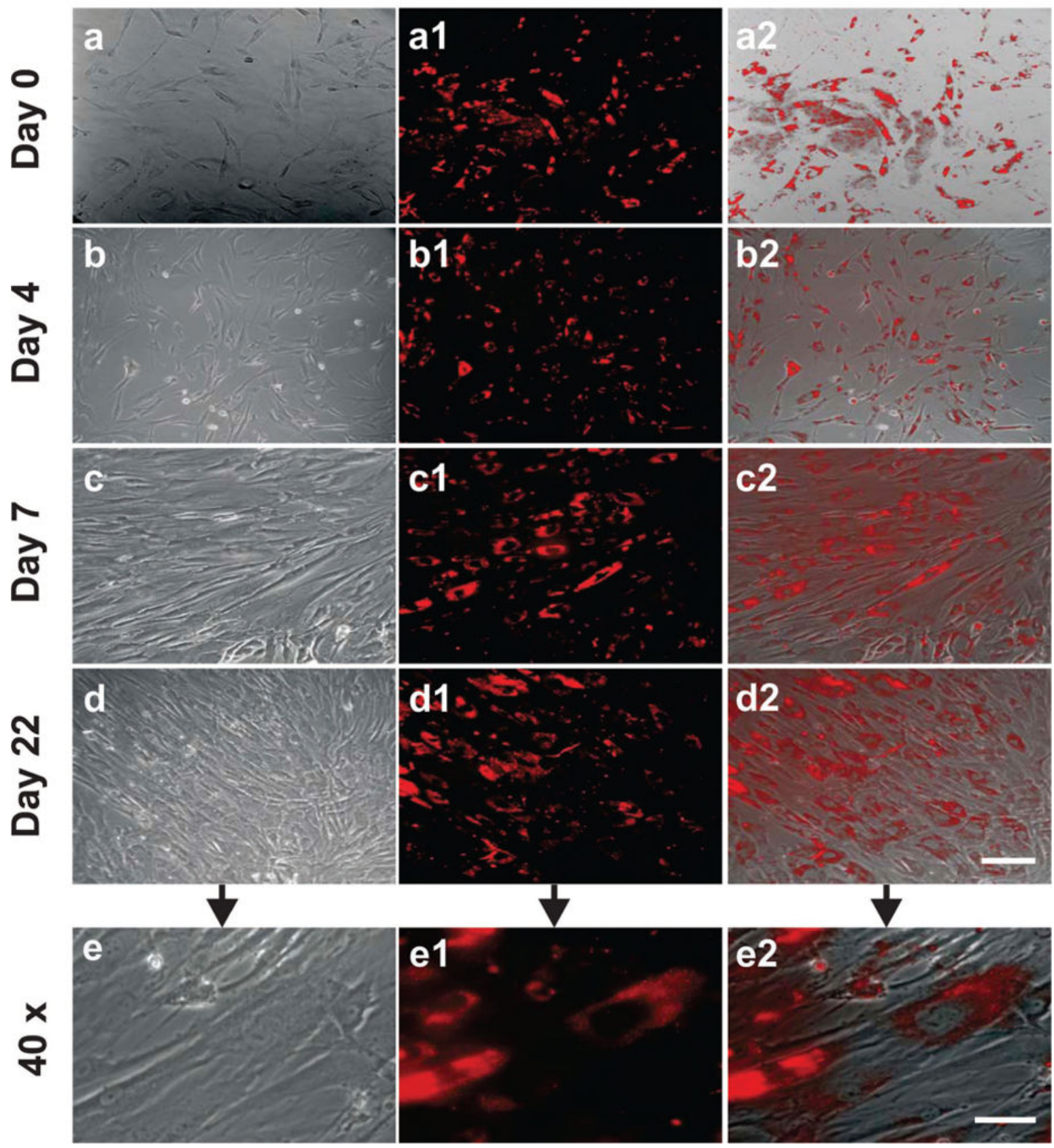

Figure 1.

Human mesenchymal stem cells (hMSCs) labeled with bioconjugated quantum dots (QDs) undergo proliferation up to the tested 22 days. hMSCs after overnight incubation with bioconjugated QDs (30 nM) (a-a2) Following the removal of extracellular QDs, QD-labeled hMSCs and unlabeled hMSCs of the same subpopulation were continuously cultured for 4 , 7, and 22 days (b-b2, c-c2, d-d2, respectively). Scale bar: $30 \mu \mathrm{m}$. QDs were internalized in the cytoplasm, even after 22 days of culture-expansion (e-e2), clearly observed in 
fluorescent (e1) and overlay (e2) images, apparently endocytosed as aggregates. Scale bar: 5 $\mu \mathrm{m}$. 

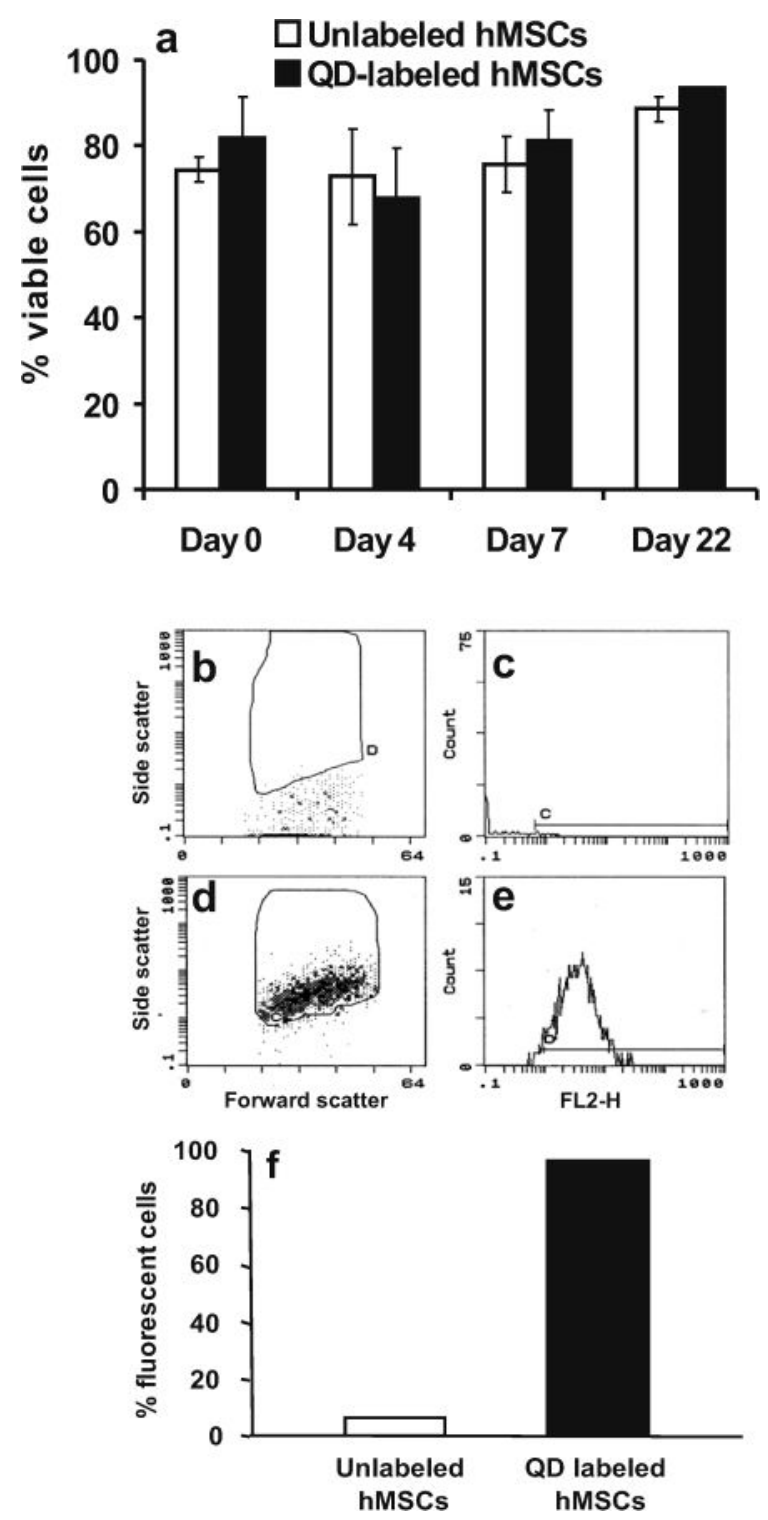

Figure 2.

Cell viability and fluorescent cell sorting. Cell viability lacked statistically significant difference between QD-labeled hMSCs and unlabeled hMSCs (a) with or without QD labeling, substantial number of hMSCs remained viable (range: 67\% to 93\%). Compared to unlabeled hMSCs $(6.5 \%)$ (b,c), fluorescence-activated sorting shows the yield of QDlabeled hMSCs at $96 \%(\mathrm{~d}, \mathrm{e})$ in the fluorescent range of $605 \pm 20 \mathrm{~nm}$ with quantitative data shown in (f). 


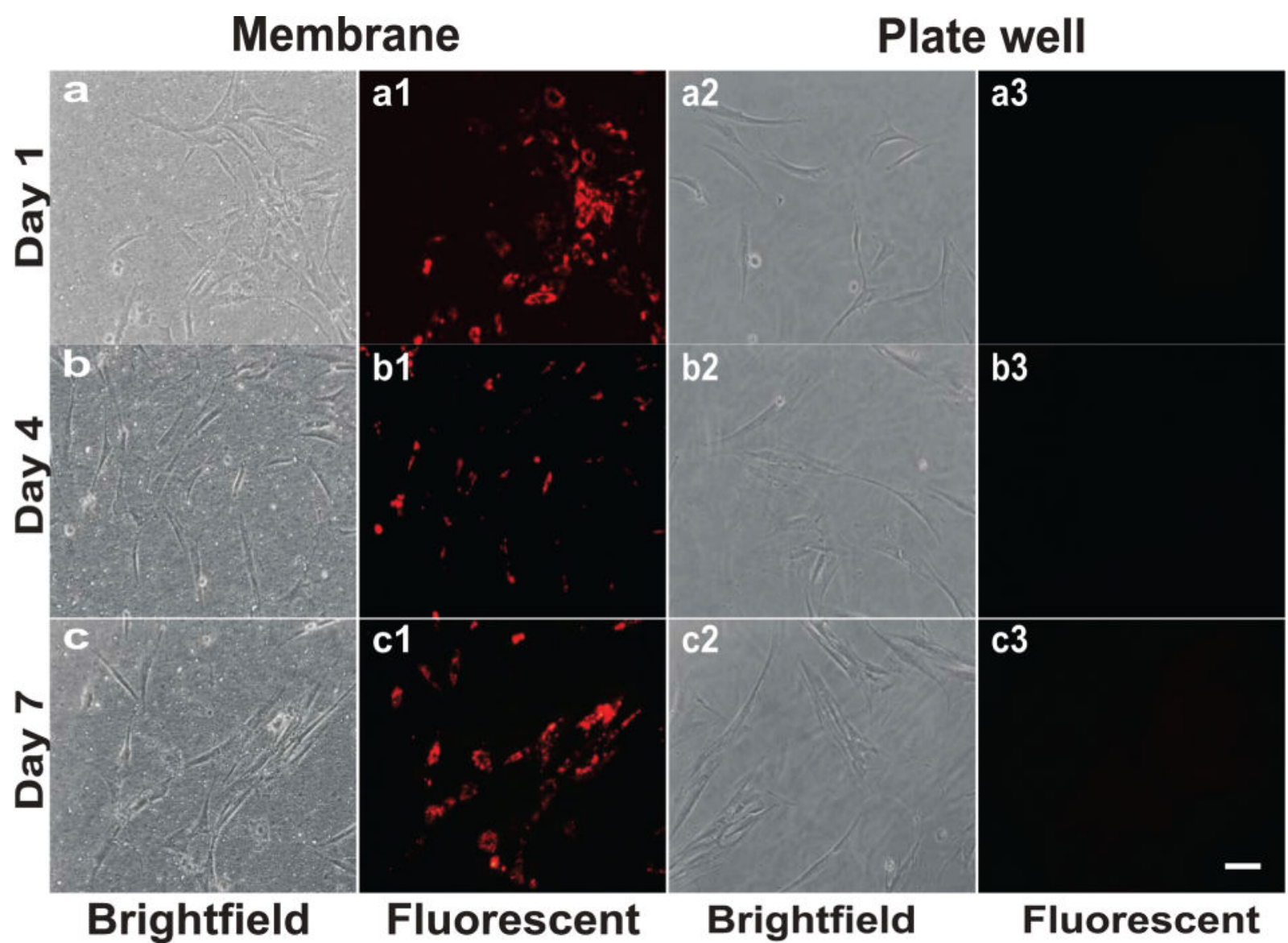

Figure 3.

Transwell culture shows a lack of cross-labeling of human mesenchymal stem cells (hMSCs) by bioconjugated quantum dots (QDs). QD-labeled hMSCs were cultured in the insert of a transwell system. The diameter of the insert is $400 \mathrm{~nm}$, much larger than the diameter of QDs in the range of 2-10 nm. Unlabeled hMSCs were cultured underneath in the transwell plate. Whereas QD-labeled hMSCs were observed under fluorescent microscope during the tested 1, 4, and 7 days (a1, b1, and c1), no apparent QD labeling was observed in the unlabeled hMSCs cultured underneath in the same medium (a3, b3, and c3). (a-c) Bright-field images of QD labeled hMSCs; (a2-c2) bright-field image of unlabeled hMSCs. These data suggest that QDs extruded by hMSCs are not taken up by the unlabeled hMSCs up to the tested 7 days of culture. Scale bar: $100 \mu \mathrm{m}$. 

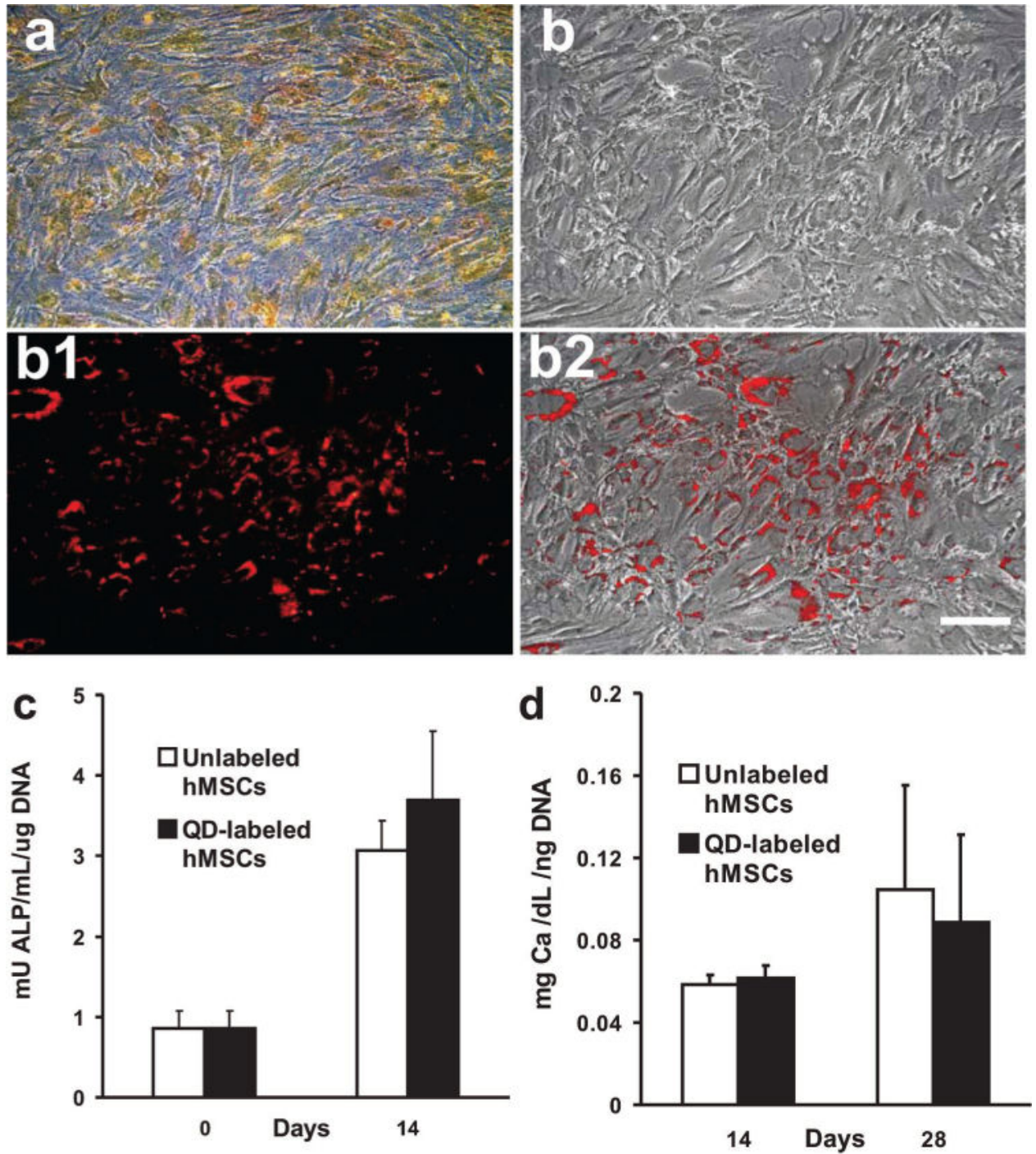

Figure 4.

Quantum dot (QD) labeling of human mesenchymal stem cells (hMSCs) during osteogenic differentiation. (a) Expression of alkaline phosphatase (ALP) during osteogenic differentiation of QD-labeled hMSCs. (b-b2) QDs remained in hMSCs during osteogenic differentiation: (b) brightfield image of hMSCs labeled with QDs; (b1) fluorescent image of b1 showing QD labeling; (b3) overlay of (b) and (b1). (c,d) No significant differences in ALP content and calcium production between QD-labeled and unlabeled hMSC-derived osteoblasts, respectively. Scale: $30 \mu \mathrm{m}$. 

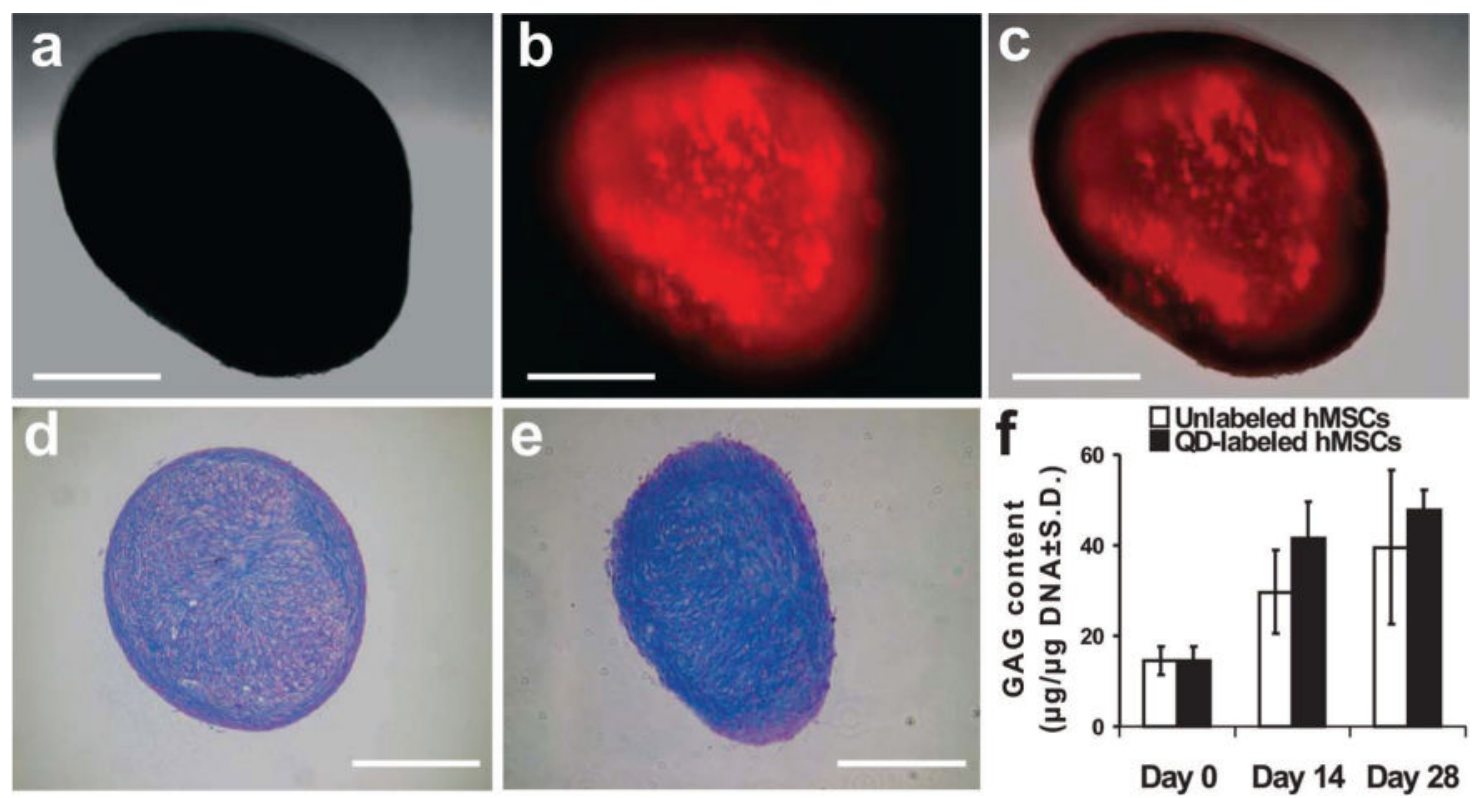

Figure 5.

Quantum dot (QD) labeling of human mesenchymal stem cells (hMSCs) during chondrogenic differentiation. (a-c) QD labeling of hMSCs during chondrogenic differentiation in pellet culture ((a) bright-field; (b) fluorescent; (c) overlay). (d,e) Positive alcian blue staining of QD-labeled or unlabeled hMSCs during chondrogenic differentiation. (f) No statistically significant difference in glycosaminoglycan (GAG) content between QDlabeled and unlabeled hMSC-derived chondrocytes. Scale bar: $250 \mu \mathrm{m}$. 

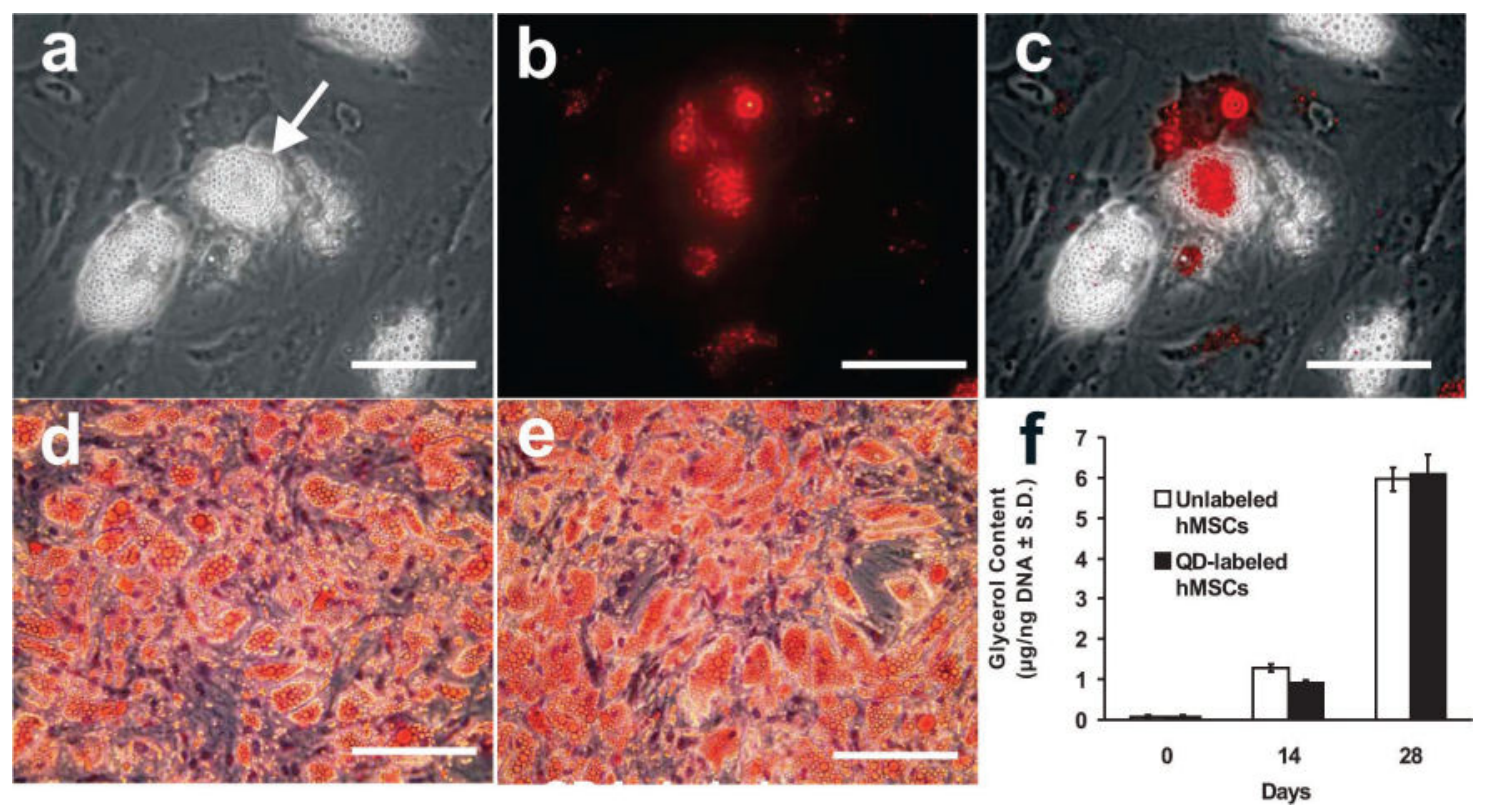

Figure 6.

Quantum dot (QD) labeling of human mesenchymal stem cells (hMSCs) during adipogenic differentiation. $(\mathrm{a}-\mathrm{c})$ Formation of intracellular lipid vacuoles in QD-labeled hMSCs during adipogenic differentiation. Arrow points to intracellular lipid vacuole. Scale bar: $50 \mu \mathrm{m}$. $(\mathrm{d}, \mathrm{e})$ Oil-red O staining showing adipogenesis formation without (d) or with (e) QD labeling. Scale bar: $100 \mu \mathrm{m}$. (f) No statistically significant difference in glycerol content between QD-labeled and unlabeled hMSC-derived adipocytes. 